\title{
PEMBELAJARAN MATA PELAJARAN AL-ISLAM DI SD MUHAMMADIYAH MRISI KABUPATEN BANTUL
}

\author{
Lukman Nur Huda \\ Alumni FAI UCY \\ Siti 'Aisyah \\ Dosen FAI UCY
}

\begin{abstract}
This evaluation study discusses the implementation of education of Al-Islam subject learning at Muhammadiyah Elementary School Mrisi, Bantul district. Supporting factors and inhibitors also become an integral part of study. The results of this qualitative study suggest developing Al-Islam subject learning in the classroom. Nevertheless the learning of other Islamic religious education (PAI) outside the classroom can have an impact on the success of learning AlIslam compared to discourage it. Such research is expected to have beneficial for the development of PAI learning in Muhammadiyah Elementary School that brings about change in achieving overall educational progress.
\end{abstract}

Keywords; Learning, Al-Islam, in classroom, outside the classroom

\begin{abstract}
Abstrak: Penelitian evaluasi ini ditujukan pada Pelaksanaan Pendidikan mata pelajaran Al-Islam di SD Muhammadiyah Mrisi kabupaten Bantul. faktor-faktor pendukung dan penghambatnya juga menjadi bagian yang tak terpisahkan. Hasil penenlitian kualitatif berupa kebutuhan terhadap pengembangan pembelajaran mata pelajaran al-islam dalam Kelas. Meski demikian pembelajaran PAI lainnya terutama di luar kelas bisa berdampak pada keberhasilan pembelajaran al-Islam dibanding menghambatnya. Penelitian demikian diharapkan bermanfaat bagi pengembangan pembelajaran PAI di SD Muhammadiyyah yang diharapkan berdampak pada kemajuan pendidikannya secara keseluruhan.
\end{abstract}

Kata kunci; Pembelajaran, al-Islam, dalam kelas, luar kelas

\section{A. Pendahuluan}

Muhammadiyah adalah salah satu organisasi sosial Islam yang terpenting di Indonesia sampai saat sekarang ini. Organisasi ini didirikan di Yogyakarta pada tanggal 18 November 1912 bertepatan dengan tanggal 8 dzulhijjah $1330 \mathrm{H}$, oleh Kyai Haji Ahmad Dahlan. ${ }^{1}$ Muhammadiyah memahami bahwa Islam merupakan pedoman hidup manusia, terutama bagi umat Islam.

${ }_{1}^{1}$ Zuhairini, Sejarah Pendidikan Islam (Jakarta: Bumi Aksara, 2011), h. 171 
Sumber utama Islam adalah Al-Quran dan As-Sunnah. setiap manusia yang berpedoman kepada keduanya, niscaya akan memperoleh kebaikan di dunia dan di akhirat, serta tidak akan tersesat untuk selamalamanya. Haroen menegaskan Islam sebagai agama wahyu menjadi pijakan absolut dalam menggapai kebenaran pengetahuan. ${ }^{2}$

Untuk dapat memahami Islam secara sistematis, terencana, dan terprogram diperlukan pendidikan yang baik. Dalam sistem pendidikan Muhammadiyah, Al-Islam secara khusus dipelajari dalam mata pelajaran Al-Islam. Karenanya, Pendidikan Al-Islam merupakan muatan pendidikan pokok dalam sistem pendidikan Muhammadiyah.

Pendidikan Al-Islam di SD Muhammadiyah juga punya keharusan. Peserta didik menjadi insan yang beriman dan bertakwa kepada Allah SWT, berakhlak mulia, mengamalkan agama Islam dalam kehidupan sehari-hari, sesuai dengan tuntunan Al-Quran dan As-Sunnah. ${ }^{3}$

Semuanya kemudian dijabarkan dalam standar kompetensi kelulusan tertulis bahwa Pendidikan Al-Islam di SD Muhammadiyah memiliki lulusan yang mampu membaca Al-Quran sesuai dengan tajwid serta menghafal beberapa surat dan hadis pilihan, mengenal rukun iman dengan mengetahui alam ghaib, tanda-tanda orang beriman dan hal-hal yang merusak iman, termasuk syirik, membiasakan perilaku terpuji sebagaimana perilaku para nabi dan rasul serta menghindari perilaku tercela, mengetahui tata cara berwudlu, shalat, puasa, zakat, dan haji sesuai dengan ketentuan Rasulullah, menceritakan kisah nabi dan rasul. ${ }^{4}$

Kondisi demikian tentu berbeda dengan tingkat pendidikan yang setara berciri keagamaan, yaitu Madrasah IBtidaiyyah. Di sana ada kecenderungan pemisahan beberapa materi keislaman sesuai bidangnya. Sebagai contoh, sejarah Islam yang masuk dalam mata pelajaran sejarah

${ }^{2}$ Hilman Haroen, "Kebenaran Pengetahuan, Antara Barat Dan Timur," Jurnal Ulumuddin 4, no. 1 (2014): 36-47.

3 Majelis Pendidikan Dasar dan Menengah Pimpinan Wilayah Muhammadiyah DIY, KTSP Pendidikan Al-Islam (Yogyakarta: t.n.p, 2008), h. 5

4 Ibid., h. 11 
kebudayaan Islam (SKI) yang memiliki pola pembelajaran berbeda dengan yang lain. 5

Dengan pola dan sistem yang telah jelas dan berjenjang. SD Muhammadiyah Mrisi Kabupaten Bantul seharusnya bisa menarik siswa lebih baik. Hal itu didukung oleh guru PAI nya yang merupakan guru bantu dari SD Negeri yang sudah sarjana sebidang ilmu. Namun SD Muhammadiyah Mrisi masih belum dijadikan sekolah pilihan oleh banyak orang tua. Kondisi itu bisa terlihat dengan jumlah siswa baru tahun ajaran 2015/2016 adalah 102 siswa. Jumlah idealnya bagi SD itu minimal memiliki 120 siswa setiap sekolah.

Sebagian mengatakan bahwa dunia pendidikan berkaitan dengan pelayanan terhadap peserta didik untuk dapat hidup yang lebih baik setelah dilayani. Guru dan dosen sebagai tenaga kependidikan harus menyadari dirinya berkewajiban akan pemberian layanan yang baik. ${ }^{6}$

Penelitian ini menjadi bagian dari hal tersebut khususnya pada pelaksanaan pembelajaran Islam di SD Muahmmadiyyah. Termasuk di dalamnya adalah penggalian tentang faktor-faktor pendukung dan penghambatnya menjadi focus dalam penelitian ini. Hal demikian bermanfaat bagi pengembangan pembelajaran PAI di SD Muhammadiyyah Mrisi yang diharapkan berdampak pada kemajuan pendidikannya secara keseluruhan.

\section{B. Metode Penelitian}

Penelitian kualitatif ini menggunakan pendekatan evaluatif sehingga bisa berdampak pada penerapan pembelajaran Keislaman yang berkelanjutan di masa depan. Dalam pelaksanaanya, data dikumpulkan dengan observasi, wawancara dan dokumentasi.

Observasi adalah pengamatan dan pencatatan secara langsung dan sistematis terhadap fenomena-fenomena obyek yang diteliti.7 Observasi

5 Makhrus Fauzi and Difla Najih, "Pembentukan Karakter Siswa Melalui Mata Pelajaran Sejarah Kebudayaan Islam Studi Kasus Madrasah Ibtidaiyah Ma'arif Giriloyo 1 Kecamatan Imogiri Bantul,” Jurnal Ulumuddin 5, no. 1 (2015): 1-8.

6Triwahyu Budiutomo, "Faktor Kepemimpinan Dalam Pembentukan Karakter Profesional Tenaga Kependidikan Triwahyu Budiutomo," Jurnal Ulumuddin 4, no. 1 (2014): 39-47.

7Sutrisno Hadi, Metode Research, vol. I (Yogyakarta: Andi Offset, 1989), h. 136. 
yang digunakan adalah observasi non partisipan, yakni peneliti tidak ikut ambil bagian dalam bidang yang ditelitinya. Metode ini digunakan penulis untuk mengumpulkan data tentang pelaksanaan Pendidikan Al-Islam di SD Muhammadiyah dan pembelajaran pendidikan Islam.

Sedang wawancara adalah pengumpulan data dengan jalan mengadakan tanya jawab sepihak yang dikerjakan dengan sistematik dan berdasarkan pada tujuan pendidikan. ${ }^{8}$ Dalam intervieu ini penulis menggunakan wawancara secara langsung dialog dengan responden yaitu guru dan Kepala SD Mihammadiyah Mrisi Desa Tirtonirmolo Kecamatan Kasihan Kabupaten Bantul. Tanya jawab atau wawancara langsung dilakukan dalam rangka mendapatkan data tentang sejarah dan perkembangan SD Muhammadiyah Mrisi Desa Tirtonirmolo Kecamatan Kasihan Kabupaten Bantul, usaha guru dalam meningkatkan pelaksanaan Pendidikan Al-Islam, kendala yang dihadapi dalam meningkatkan pelaksanaan Pendidikan Al-Islam.

Pengumpulan data juga menggunakan dokumentasi adalah metode pengumpulan data dengan jalan mengumpulkan catatan, transkrip, bukubuku, suratkabar, majalah, prasasti, notulen rapat, legger, agenda dan lain sebagainya. 9 Pemanfaatannya untuk memperoleh data-data mengenai gambaran umum SD Muhammadiyah Mrisi Desa Tirtonirmolo Kecamatan Kasihan Kabupaten Bantul, antara lain mengenai daftar pengasuh (guru), karyawan dan siswa.

Data kemudian dianalisisi secara induktif. Caranya berangkat dari fakta-fakta yang khusus, peristiwa-peristiwa yang kongkrit, kemudian dari fakta-fakta atau peristiwa peristiwa yang kongkrit itu ditarik generalisasigeneralisasi yang mempunyai sifat umum. ${ }^{10}$ Analisa data ini bermula dari analisis terhadab data-data Pendidikan Al-Islam kemudian ditarik kesimpulan dari data lapangan tersebut sehingga menjadi kesimpulan yang bersifat umum.

\section{A. Tinjauan Pelaksanaan Pendidikan Agama Islam}

8Ibid. h. 132

9Ibid. h. 135

10Ibid. 
Dalam penjabarannya, bagian ini diawali dengan penjabaran teori tentang Pendidikan Islam. Termuat didalamnya pengertian, tujuan dan materi pemebelajaran al-Islam. Selanjutnya diuraikan tentang kajian teoritis tentnag factor-faktor yang biasa menjadi pengahambat dan pendukung pembelajaran.

1. Pelaksanaan Pendidikan Al-Islam

a. Pengertian Pelaksanaan pembelajaran

Proses belajar mengajar atau proses pembelajaran meliputi kegiatan yang dilakukan guru mulai dari perencanaan, pelaksanaan kegiatan sampai evaluasi dan program tindak lanjut yang berlangsung dalam situasi edukatif untuk untuk mencapai tujuan tertentu yaitu pengajaran. ${ }^{11}$ Nana Sudjana menjabarakan pelaksanaannya bertahap sebagai berikut:

1) Tahap pra Instruksional

Yakni tahap yang di tempuh pada saat memulai sesuatu proses pembelajaran, yaitu:

a) Guru menanyakan kehadiran siswa dan mencatat siswa yang tidak hadir

b) Bertanya kepada siswa sampai dimana pembahasan sebelumnya

c) Memberikan kesempatan kepada siswa untuk bertanya mengenai bahan pelajran yang belum dikuasainya, dari pelajaran yang sudah disampaikan.

d) Mengajukan pertanyaan kepada siswa berkaitan dengan bahan yang sudah diberikan

e) Mengulang bahan pelajaran yang lain secara singkat tatapi mencakup semua aspek bahan

2) Tahap Instruksional

Yakni tahap pemberian bahan pelajaran yang dapat diidentifikasikan beberapa kegiatan sebagai berikut:

a) Menjelaskn kepada siswa tujuan pengajaran yang harus dicapai siswa

b) Menjelaskan pokok materi yang kaan dibahas

c) Membahas pokok materi yang sudah dituliskan 1997), h. 19

${ }^{11}$ Suryosubroto, Proses Belajar Mengajar Di Sekolah (Jakarta: Rineka Cipta, 
d) Pada setiap pokok materi yang dibahas sebaiknya diberikan contohcontoh yang kongkret, pertanyaan, tugas

e) Penggunaan alat bantu pengajaran untuk memperjelas pembahasan padda setiap materi pelajaran

f) Menyimpulkan hasil pembahasan dari semua pokok materi.

3) Tahap Evaluasi dan Tindak Lanjut

Mekanisme adalah sebagai berikut;

a) Mengajukan pertanyaan kepada kelas atau kepada beberapa murid mengenai semua aspek pokok materi yang telah dibahas pada tahap instruksional

b) Apabila pertanyaan yang diajukan belum dapat dijawab oleh siswa (kurang dari 70\%), maka guru harus mengulang pengajaran

c) Untuk memperkaya pengetahuan siswa mengenai materi yang dibahas, guru dapat memberikan tugas atau PR

d) Akhiri pelajaran dengan menjelaskan atau memberitahukan poko materi yang akan dibahas pada pelajaran berikutnya. ${ }^{12}$

b. Pengertian Pendidikan Al-Islam

Pendidikan memiliki beberapa istilah diantaranya: ta'dib, ta'lim, dan tarbiyah. Ta'dib artinya membuat agar menjadi beradab, ta'lim artinya pengajaran maksudnya pemberian atau penyampaian pengetahuan dari seseorang kepada orang lain agar menjadi pandai berwawasan luas dan lain-lain, tarbiyah artinya mendidik.13 Pada UU No. 20 th 2003 pendidikan adalah usaha sadar dan terencana untuk mewujudkan suasana belajar dan proses pembelajaran agar peserta didik secara aktif mengembangkan potensi dirinya untuk memiliki kekuatan spiritual keagamaan, pengendalian diri, kepribadian, kecerdasan, akhlak mulia, serta keterampilan yang diperlukan dirinya, masyarakat, bangsa, dan negara. ${ }^{14}$

${ }^{12}$ Ibid., h. 36-37

${ }_{13}$ Nur Uhbiyati, Dasar-Dasar Ilmu Pendidikan Islam (Semarang: Pustaka Rizki Putra, 2013), h. 13-15

14 Hasbullah, Dasar-Dasar Ilmu Pendidikan (Jakarta: Raja Grafindo Persada, 2012), h. 4 
Pendidikan Al-Islam menurut Muhammadiyah adalah memiliki fungsi utama membina mengantarkan peserta didik menjadi insan yang beriman dan bertakwa kepada Allah SWT, berakhlak mulia, mengamalkan ajaran Islam dalam kehidupan sehari-hari, sesuai dengan tuntunan AlQur'an dan As-Sunnah.15 Adapun Tujuannya adalah sebagai berikut;

1) Menumbuh-kembangkan akidah Islam melalui pemberian, pemupukan, dan pengembangan pengetahuan, penghayatan, pengamalan, pembiasaan, serta pengalaman peserta didik tentang AlIslam sehingga menjadi manusia muslim yang harus berkembang keimanan dan ketakwaannya kepada Allah SWT, sesuai Al-Quran dan As-Sunnah.

2) Mewujudkan manusia Indonesia yang taat beragama dan berakhlakul karimah, yaitu manusia yang berpengetahuan, rajin beribadah, cerdas, produktif, kreatif, inovatif, jujur, adil, etis, berdisiplin, bertoleransi (tasamuh), menjaga keharmonisan secara personal dan sosial serta mengembangkan budaya Islami dalam komunitas sekolah/madrasah sesuai Al-Quran dan As-Sunnah. ${ }^{16}$

Pendidikan Al-Islam kemudian merupakan upaya sadar, terencana dan sistematis dalam menyiapkan peserta didik untuk mengenal, memahami, dan menghayati Agama Islam agar beriman, bertakwa dan berakhlak mulia, mengamalkan ajaran Agama Islam melalui kegiatan bimbingan, pengajaran dan pelatihan serta pengalaman. Aspek materinya meliputi; Al-Qur'an/Al-Hadis, Aqidah, Akhlak, Ibadah/Mu'amalah dan Tarikh.Setiap aspek mata pelajaran terdiri dari beberapa materi agama yang terdapat di Kurikulum KTSP. ${ }^{17}$

c. Faktor-faktor yang mempengaruhi keberhasilan

Secara global, faktor-faktor yang mempengaruhi belajar siswa dapat dibedakan menjadi tiga jenis, yakni:

a. Faktor Internal (faktor dari dalam siswa), yakni keadaan/kondisi jasmani dan rohani siswa

15 Majelis Pendidikan Dasar dan Menengah Pimpinan Wilayah Muhammadiyah DIY, KTSP Pendidikan Al-Islam, h. 5

16Ibid., h. 7

17 Ibid., 
b. Faktor Eksternal (faktor dari luar siswa), yakni kondisi lingkungan di sekitar siswa

c. Faktor Pendekatan belajar (approach to learning), yakni jenis upaya belajar siswa yang meliputi strategi dan metode yang digunakan siswa untuk melakukan kegiatan mempelajari materi-materi pelajaran. ${ }^{18}$

\section{Pelaksanaan Pendidikan Al-Islam}

Proses pembelajaran pendidikan Al-Islam di SD Muhammadiyah Mrisi menggunakaan kurikulum KTSP Pendidikan Al-Islam dari Majelis Dikdasmen PWM DIY tahun 2012. Liputannya adalah silabus, yang dapat digunakan untuk membuat Rencana Pelaksanaan Pembelajaran (RPP), sehingga langkah-langkah pembelajaran, kegiatan inti pembelajaran, kegiatan akhir pembelajaran, evaluasi yang diadakan dan metode yang akan diterapkan dalam Pendidikan Al-Islam tersebut terencana dan berjalan sesuai dengan yang diharapkan guru .

1. Perencanaan pembelajaran

Perencanaan pembelajaran merupakan tahap pra interaksi sebelum guru berinteraksi dengan siswa. Guru PAI SD Muhammadiyah Mrisi tidak menyusun Rencana Pelaksanaan Pembelajaran yang merupakan rencangan dari silabus yang sudah ada di Kurikulum KTSP Pendidikan AlIslam. Sehingga kegiatan pembelajaran seperti kegiatan pendahuluan, kegiatan inti dan kegiatan penutup hanya berjalan sesuai dengan pengalaman dan kebiasaan mengajar selama di SD Muhammadiyah Mrisi.

2. Pelaksanaan Pembelajaran Pendidikan AL-Islam

Pembelajaran al-Islam di SD Muhammdaiyah terlakasan selama 5 jam pelajaran per minggu. Kondisi kegiatan pembelajaran cenderung tidak mengalami perubahan. Pemeblajaran dalam kelas dimana siswa duduk di bangku dengan susunan empat banjar. Khusus di SD Muhammadiyah Mrisi tidak memiliki langkah-langkah pembelajaran tertentu. Kegiatan pendahuluan, kegiatan inti, kegiatan penutup, evaluasi yang diadakan dan metode yang diterapkan berjalan sesuai dengan kebiasaan guru mengajar. a. Awal Pembelajaran

\footnotetext{
18Muhibbin Syah, Psikologi Pendidikan Dengan Pendekatan Baru (Bandung: PT Remaja Rosdakarya, 2014), h. 129
} 
Guru PAI SD Muhammadiyah mengawali pembelajaran setelah memasuki ruang kelas guru membuka dengan salam dan membaca basmalah. Keegiatan lanjutan berupa tadarus surat-surat yang berhubungan dengan materi Al-Qur'an dalam Pendidikan Al-Islam.

Kegiatan demikian bermanfaat saat siswa menerima materi pembelajaran yang baru siswa diingatkan materi yang sudah dipelajari. Sehingga akan membantu siswa dalam menguatkan memori materi pembelajaran yang sudah didapatkan. Kegiatan sesudahnya adalah penjelasan guru tentang materi yang akan dipelajari dan menjelaskan tujuan yang hendak dicapai. Kemudian guru bertanya untuk mengetahui kemampuan siswa terhadap materi yang akan dipelajari.

b. Pertengahan Pembelajaran

Dalam memberikan materi dilakukan secara klasikal oleh guru, diawali dari ceramah. Sumber pembelajaran yang digunakan adalah buku paket Pendidikan Al-Islam yang diterbitkan dari Majelis Pendidikan Dasar dan Menengah Pimpinan Wilayah Muhammadiyah Yogyakarta. Siswa menulis materi yang penting atau guru menulis materi di papan tulis dengan kapur kemudian guru menerangkan materi Al-Islam.

c. Akhir Pembelajaran

Kegiatan akhir pembelajaran meliputi penyimpulan materi yang sedang diberikan, menilai hasil kerja siswa, evaluasi, dan salam. perlu dilakukan evaluasi setiap selesai pembelajaran untuk mengetahui sejauh mana siswa menguasai materi yang telah disampaikan. Agar guru bisa memutuskan untuk melanjukan materi selanjutnya atau mengulang materi sampai siswa menguasainya.

Dalam rangkaian pembelajaran al-Islam satu semester ternyata evalauasi cukup lengkap. Kegiatan dilakukan dengan mengadakan test lisan, tertulis, dan pengamatan. Cakupannya juga luas, yaitu;

1) Aspek Kognitiftif, berupa tugas-tugas sesuai dengan materi yang sudah diajarkan untuk menilai pengetahuan siswa.

2) Aspek Psikomotorik, melalui pengamatan kemampuan siswa dalam mempraktekan materi yang sudah diajarkan, untuk mengetahui ketrampilan siswa 
3) Aspek Affektif, Dilakukan dengan memberikan pertanyaan-pertanyaan yang bersifat kebiasaan, untuk mengatahui sikap siswa.

Evaluasi pembelajaran juga dilakukan setiap semester dan pada setiap tengah semester diadakan Ujian Tengah Semeter (UTS). Evaluasi yang dilakukan guru menunjang bagi peningkatan mutu Pendidikan AlIslam di SD Muhammadiyah kemudian disajikan dalam bentuk raport yang dilaporkan kepada wali murid tiap semesternya.

\section{Faktor Pendukung dan Penghambat Pelaksanaan Pendidikan}

\section{Al-Islam}

Selama pembelajaran al-Islam selalu ditemukan hal-hal yang dapat mendukung maupun menghambat proses pembelajaran menuju pencapaian tujuan. Karena pengalaman dan perjalanan waktu, para guru bisa menyimpulkan dan kadang juga menyelesisakan dan mengembangkan proses tersebut.

\section{Faktor Pendukung}

Pembelajaran PAI pada SD Muhammadiyah sangat kompleks. Meski demikian, semuanya mendukung agar mata pelajaran al-Islam bisa berjalan sesuai perncanaan mencapai tujuannya. Beberapa temuan factor keberhasilan bisa dijabarkan.

a. Siswa yang sehat secara fisik dan psikis.

Karena itu mereka juga bisa berprestasi dengan kondisi yang ada. Dari hasil rapot untuk nilai Pendidikan Al-Islam sepeti pelajaran AlQuran, Aqidah, Akhlak, Ibadah dan Tarikh semua siswa mendapat nilai rapot diatas kriteria ketuntasan milinal (KKM) yaitu 75 keatas. Dari mengikuti perlombaan keagamaan atau MTQ beberapa ada siswa yang juara.

TABEL 1

PRESTASI KEAGAMAAN SISWA

\begin{tabular}{|c|c|c|c|c|c|}
\hline No & Juara & Nama Lomba & Acara & Tingkat & Waktu \\
\hline 1 & II & Adzan & $\begin{array}{c}\text { Jambore } \\
\text { Daerah \# } 3\end{array}$ & Kab. Bantul & Jun-14 \\
\hline 2 & I & CCA & MTQ & Kec. & Agu-14 \\
\hline
\end{tabular}




\begin{tabular}{|c|c|c|c|c|c|}
\hline & & & & Kasihan & \\
\hline 3 & II & Tartil Putri & MTQ & $\begin{array}{c}\text { Kec. } \\
\text { Kasihan }\end{array}$ & Agu-14 \\
\hline 4 & III & Pildacil & HKSN & Des-14 \\
\hline 5 & II & Da'i Cilik & SILASKOTA 12 & DIY & Des-14 \\
\hline 6 & III & CCA & SILASKOTA 12 & DIY & Des-14 \\
\hline 7 & II & CCA & SPAT & Jan-15 \\
\hline 8 & I & Pildacil & $\begin{array}{c}\text { FAS Badko } \\
\text { Kasihan }\end{array}$ & $\begin{array}{c}\text { Kec. } \\
\text { Kasihan }\end{array}$ \\
\hline
\end{tabular}

b. Guru pengajar sesuai dengan kebutuhan Pembelajaran al-Islam.

Para guru itu sudah lama mengajar di SD Muhammadiyyah. Mereka bahkan diangkat sebagai PNS dan diperbantukan di situ. Mereka kemudian sudah berpengalaman. Selain itu didukung pula bahwa latar belakang pendidikan tingginya sebidang. Semuanya telah bergelar Sarjana Agama dan Sarjana Pendidikan Islam.

c. Sarana dan prasarana mencukupi

Tempat dan ruangan yang digunakan untuk proses belajar mengajar di SD Muhammadiyah sangat memadai/mendukung, karena sudah ada ruangan masing-masing dalam pembelajaran dan didukung adanya tempat ibadah yang representatif yakni sebuah masjid serta sarana lain yang diperlukan. Dengan demikian dapat dipisahkan antara kelompok siswa sesuai kelas masing-masing akan sangat mendukung berlangsungnya proses belajar mengajar

d. Ada program belajar yang memberikan bekal kecerdasan yang agamis sosial

Caranya dengan pembiasaan untuk peduli kepada sesama yang dilatih memberikan infak setiap hari senin dan hari jumat, zakat fitrah, pemberian daging kurban dll. Untuk melatih kecerdasan dan meningkatkan keimanan dengan tadarus 15 menit setiap pagi setelah masuk kelas, pesantren kilat yang dilaksanakan setahun 1 kali pada setiap Bulan Ramadhan.

e. Pembelajaran baca tulis al-Quran. 
Taman Pendidikan Al-Qur'an (TPA) dilaksanakan di luar kegiatan belajar mengajar formal yaitu pada jam ke nol dan sore hari. TPA pagi dimulai pukul 6.30 sampai pukul 7.00 wib. Karena realitanya anak-anak sulit datang jam 6.00 pagi termasuk pengajarnya. Peserta didik membaca IQRO’ secara privat, dan bisa keluar kelas. Untuk TPA sore peserta didik diwajibkan dan dianjurkan untuk berangkat. Tetapi realitanya masih banyak peserta didik SD Muhammadiyah Mrisi tidak berangkat TPA sore.

TABEL 2

JADWAL LATIHAN SHALAT

\begin{tabular}{|c|c|c|c|}
\hline NO & KELAS & HARI & PUKUL \\
\hline 1 & SATU & SELASA & $06.00-07.00$ WIB \\
\hline 2 & DUA & SELASA & $06.00-07.00$ WIB \\
\hline 3 & TIGA & KAMIS & $06.00-07.00$ WIB \\
\hline 4 & EMPAT & JUM'AT & $06.00-07.00$ WIB \\
\hline 5 & LIMA & RABU & $06.00-07.00$ WIB \\
\hline 6 & ENAM & RABU & $06.00-07.00$ WIB \\
\hline 7 & SATU- & SENIN & $16.00-17.00$ WIB \\
& ENAM & & \\
\hline 8 & SATU- & JUMAT & $16.00-17.00$ WIB \\
& ENAM & & \\
\hline
\end{tabular}

f. Pembiasaan untuk pembentukan akhlak dan budi pekerti yang luhur serta melatih kemandirian Siswa dilaksanakan diluar pembelajaran Pendidikan Al-Islam.

Disamping kegiatan belajar mengajar seperti biasa di SD Muhammadiyah, juga diadakan pembiasaan jabat tangan pada setiap masuk pagi di depan pintu gerbang, disetiap anak sampai di sekolah sudah ada guru yang ditugaskan piket jaga di depan gerbang satu atau dua orang, setiap peserta didik tiba mereka berjabat tangan dan menaruh tangan guru ke pipi mereka, dan pulang sekolah juga dilakukan berjabat tangan dengan guru yang ada di kelas dilanjutkan dengan guru yang ada di kantor, kegiatan ini untuk pembiasaan silaturrahim dan sopan santun kepada sesama terlebih kepada orang tua.

g. program latihan shalat dan shalat dhuhur berjama'ah

Kegiatan rutinitas di luar kelas dalam rangka mendukung pembelajaran PAI di SD Muhammadiyah juga diadakan. Program latihan 
shalat dan shalat dhuhur berjama'ah untuk kelas atas. Dengan harapan siswa mampu mengenal Allah SWT lebih mendalam.

TABEL 3

JADWAL LATIHAN SHALAT

\begin{tabular}{|c|c|c|c|c|}
\hline NO & KELAS & HARI & WAKTU & KETERANGAN \\
\hline 1 & SATU & SELASA & $09.10-09.30$ WIB & $\begin{array}{c}\text { JAM PAI/ } \\
\text { ISTIRAHAT }\end{array}$ \\
\hline 2 & DUA & RABU & $09.40-10.00$ WIB & $\begin{array}{c}\text { ISTIRAHAT/ JAM } \\
\text { PAI }\end{array}$ \\
\hline 3 & TIGA & KAMIS & $09.20-09.35$ WIB & ISTIRAHAT \\
\hline 4 & EMPAT & JUM'AT & $09.20-09.35$ WIB & ISTIRAHAT \\
\hline 5 & LIMA & SENIN & $09.10-09.30$ WIB & $\begin{array}{c}\text { JAM PAI/ } \\
\text { ISTIRAHAT }\end{array}$ \\
\hline 6 & ENAM & SELASA & $10.45-11.00$ WIB & ISTIRAHAT \\
\hline
\end{tabular}

Kegiatan latihan shalat berjalan dengan lancar dan diikuti semua siswa. Anak terlebih dahulu wudlu kemudian dilaksanakan shalat berjamaah dua rokaat dengan siswa yang menjadi imam. Bacaan shalat dibaca keras, sehingga guru mendengar dan dapat mengontrol bacaan peserta didik. Kegiatan ini juga membantu hafalan surat-surat pendek siswa karena surat yang dibaca disesuaikan dengan silabus materi AlQuran kelas tersebut.

Untuk shalat dhuhur berjamaah sendiri penulis melihat bahwa shalat dilaksanakan antara kelas 3 sampai kelas 6. Shalat dilaksanakan dengan kebijakan guru kelas karena kadang-kadang ada shalat dhuhur berjamaah kloter kedua. Kegiatan latihan shalat ini sangat membantu pembelajaran Pendidikan Al-Islam yang harus memiliki kompetensi kelulusan yang mengetahui tata cara shalat, dan hafalan surat-surat pilihan. Untuk kegiatan shalat dhuhur berjamaah penulis menganalisis bahwa kegiatan sangat baik dalam pendidikan Akhlak kepada Allah dengan melaksanakan shalat fardhu pada waktunya.

\section{Faktor Penghambat}

Selain factor pendukung, ada beberapa kondisi yang harus diperhatikan oleh para guru agar pencapaian tujuan pembelajaran alIslam bisa dicapai. Kondisi itu perlu segera dibahas untuk diketahui penyebabnya dan bagaimana menyelesaikannya. Faktor penghambat itu dapat diutarakan di sini. 
a. Keterbatasan Fisik dari sebagaian siswa

Diantara yang mengalami keterbatasan ada pada mata meski tidak mencapai derjat kebutaan. Siswa tersebut perlu membaca perlu jarak yang sangat dekat

b. Alokasi waktu terbatas

Yang tersedia untuk melaksanakan Pendidikan Al-Islam tidak sesuai dengan banyak materi bagian, seperti Al Qur'an, Aqidah, Akhlak, Ibadah, dan Tarekh. kecukupan dalam seminggu dialokasikan waktu 5 jam pelajaran, apalagi setiap materi dengan 1 jam pelajaran setiap minggunya, dengan demikian pelaksanaan maupun capaian hasil pun kurang maksimal bahkan jauh dari yang diinginkan.

c. Sumber belajar belum merata.

Sebagian Siswa belum mempunyai buku pegangan. Kondisi ini berdapak pada pelambatan pembelajaran yang berpotensi hasil pembelajaran Pendidikan Al-Islam kurang optimal

d. Fasilitas buku, alat peraga maupun media pembelajaran masih minim

Yang berhubungan dengan Pendidikan Al-Islam perlu ditambah karena kurang memadai dalam proses belajar mengajar Pendidikan AlIslam. Ditambah dengan tidak adanya buku pegangan siswa membuat pembelajaran Pendidikan Al-Islam berjalan lambat dalam proses pembelajaran.

e. Kurangnya perhatian dari wali murid

terhadap peserta didik dalam Pendidikan Al-Islam, sehingga terkesan siswa diberikan sepenuhnya tanggungjawab kepada guru sehingga pembelajaran dan hasil pembelajaran belum optimal.

\section{E. Kesimpulan}

Pelaksanaan Pendidikan Al-Islam di SD Muhammadiyah Mrisi Kabupaten Bantul menggunakan Kurikulum KTSP Pendidikan Al-Islam dari Majelis DIKDASMEN PWM DIY. Meski demikian, Silabus yang ada belum dijabarkan untuk membuat rencana pelaksanaan pembelajaran dalam Kelas. Langkah pembelajaran terdiri dari kegiatan pendahuluan, inti pembelajaran, kegiatan akhir pembelajaran berjalan dengan baik, evaluasi dilakukan di akhir pembelajaraan, evaluasi tengah semester dan 
akhir semester. Metode yang diterapkan dalam pembelajaran Pendidikan Al-Islam adalah metode ceramah dan tanya jawab. Untuk materi Pendidikan Al-Islam terdapat 5 aspek yaitu: Al-Qur'an, Aqiah, Akhlak, Ibadah dan Tarikh.

Meski demikian PAI lainnya di SD Muhamadiyah memberikan dampak pada pembelajaran al-Islam. Ragam PAI selain dalam kelas didukung dengan pembelajaran luar kelas. pelaksanaannya bahkan bekerja sama dengan lembaga pendidikan lain bisa berdampak pada keberhasilan pembelajaran al-Islam dibanding menghambatnya.

Sebagai saran, Hidayat memberikan catatan penting tentang inhouse training yang berguna bagi pembelajaran siswa, termasuk al-Islam. Sistem peningkatan pengetahuan itu bagi guru bisa dilakukan secara tersistem dan berkelanjutan. Mereka juga harus siap untuk memperbaiki dan meningkatkan mutu kinerjanya agar memiliki kompetensi yang optimal dalam usaha membimbing siswa agar siap menghadapi masyarakat dan bahkan mampu memberikan contoh tauladan bagi siswanya. ${ }^{19}$

\section{Daftar Pustaka}

Budiutomo, Triwahyu. "Faktor Kepemimpinan Dalam Pembentukan Karakter Profesional Tenaga Kependidikan Triwahyu Budiutomo.” Jurnal Ulumuddin 4, no. 1 (2014): 39-47.

Fauzi, Makhrus, and Difla Najih. "Pembentukan Karakter Siswa Melalui Mata Pelajaran Sejarah Kebudayaan Islam Studi Kasus Madrasah Ibtidaiyah Ma'arif Giriloyo 1 Kecamatan Imogiri Bantul.” Jurnal Ulumuddin 5, no. 1 (2015): 1-8.

Hadi, Sutrisno. Metode Research. Vol. I. Yogyakarta: Andi Offset, 1989.

Haroen, Hilman. "Kebenaran Pengetahuan, Antara Barat Dan Timur." Jurnal Ulumuddin 4, no. 1 (2014): 36-47.

Hidayat, Fattah."Kinerja Guru Dalam Perspektif Psikologi Organisasi," Jurnal Ulumuddin Volume 5, Nomor 1, Juni 2015, p. 39-47

Hasbullah. Dasar-Dasar Ilmu Pendidikan. Jakarta: Raja Grafindo Persada, 2012.

Majelis Pendidikan Dasar dan Menengah Pimpinan Wilayah Muhammadiyah DIY. KTSP Pendidikan Al-Islam. Yogyakarta: t.n.p, 2008.

Suryosubroto. Proses Belajar Mengajar Di Sekolah. Jakarta: Rineka Cipta, 1997.

Syah, Muhibbin. Psikologi Pendidikan Dengan Pendekatan Baru. 
Bandung: PT Remaja Rosdakarya, 2014.

Uhbiyati, Nur. Dasar-Dasar Ilmu Pendidikan Islam. Semarang: Pustaka Rizki Putra, 2013.

Zuhairini. Sejarah Pendidikan Islam. Jakarta: Bumi Aksara, 2011. 